\title{
The Paradox of Charity
}

\section{MARCIN LEWIŃSKI}

\author{
ArgLab, Institute of Philosophy of Language (IFL) \\ Universidade Nova de Lisboa \\ Avenida de Berna 26 \\ 1069-061 Lisbon \\ Portugal \\ m.lewinski@fcsh.unl.pt
}

\begin{abstract}
The principle of charity is used in philosophy of language and argumentation theory as an important principle of interpretation which credits speakers with "the best" plausible interpretation of their discourse. I contend that the argumentation account, while broadly advocated, misses the basic point of a dialectical conception which approaches argumentation as discussion between (at least) two parties who disagree over the issue discussed. Therefore, paradoxically, an analyst who is charitable to one discussion party easily becomes uncharitable to the other. To overcome this paradox, I suggest to significantly limit the application of the principle of charity depending on contextual factors.
\end{abstract}

Résumé: Le principe de charité est utilisé dans la philosophie du langage et la théorie de l'argumentation comme un principe important d'interprétation qui attribue aux interlocuteurs "la meilleure" interprétation plausible de leur discours. Je soutiens que la justification de ce principe par la théorie d'argumentation, alors que globalement préconisée, ne saisit pas l'idée principale d'une conception dialectique qui examine l'argumentation comme une discussion entre (au moins) deux interlocuteurs qui sont en désaccord sur le point en litige. Par conséquent, paradoxalement, un analyste qui est charitable envers un interlocuteur devient facilement non charitable envers l'autre. Pour éliminer ce paradoxe, je suggère de limiter significativement l'application du principe de charité en fonction des facteurs contextuels.

Keywords: dialectics, interpretation, paradoxes, principle of charity, strategic maneuvering 


\section{Introduction}

The principle of charity has entered argumentation theory as a loan-concept, so to speak, from philosophy of language. In both disciplines it is a principle applicable in the process of interpretation of others' discourse. It guides an "interpreter" into giving the "interpretees" the benefit of the doubt, in the sense of crediting them with the most rational (truthful, coherent, logically valid) interpretation of expressions that for some reason evade straightforward, unequivocal interpretation. Beyond this general characterization, however, the functions of the principle of charity (henceforth PC) differ considerably in philosophy of language and argumentation theory. Govier, having analyzed the philosophical conceptions of charity, goes as far as saying that "on reflection there seems only a tenuous connection between these broad philosophical contexts and the particular context of argument analysis" (1987: 114). Even if tenuous, this connection merits a brief reexamination, if only in order to clearly distinguish between various formulations of PC and highlight both their strengths and vulnerabilities (Section 2). On the basis of this critical overview, I will be in a position to specifically identify a problem in a consistent application of PC in the dialectical analysis and evaluation of argumentation that I term the paradox of charity (Section 3). Subsequently, I will propose a possible way out of the paradox by arguing for a minimal PC that is applied by argument analysts exclusively: (1) in cases of irresolvable interpretative doubt and directed either (2a) to discourse of but one dialectical party, the protagonist, in what I call constructive contexts, or ( $2 b)$ to discourse of the other party, the antagonist, only in critical contexts (Section 4). The principle so weakened can possibly resolve the paradox of charity in the dialectical analysis and evaluation of argumentation. Finally, I will argue that while my discussion takes as a starting point dialectical approaches that, following Aristotle, define argumentation as a critical and largely competitive activity, its elements have broader application compatible with consensual dialectical approaches (Section 5).

\section{The principle of charity in philosophy of language and argumentation theory}

Philosophers formulated PC in their quest for a well-founded answer to a basic question of how to understand the other (Da- 
vidson 1973, 1974; Dennett 1971; ${ }^{1}$ Gauker 1986; Lewis 1974; Quine 1960: Ch. 2; Wilson 1959). The basic idea behind PC seems rather simple: without the charitable assumption that people are in principle rational (truthful, coherent) in their use of language, any consistent understanding of the other, and thus meaningful communication, is quite impossible. The philosophical inquiry into the conditions of the possibility for rational interpretation (consisting of belief and meaning attribution) usually takes place by means of a thought experiment in which an interpreter is confronted with the task of understanding a language completely foreign to him, without recourse to any translators. Such an idealized process of "radical translation" (Quine 1960) or "radical interpretation" (Davidson 1973) apart from linguistic and extra-linguistic data, requires some methodical constraints that support the process in the critical moments of doubt and less than full knowledge (which are permanently inscribed in the task of understanding an unknown language). One such necessary constraint is $\mathrm{PC}$, which requires that we, as interpreters, hold the speakers of the interpreted language right and consistent by our own standards with a view to the empirical data at our disposal.

Davidson, arguably the most influential proponent of PC, introduces it as a necessary element of his theory of radical interpretation $(1973,1974,1982 / 2004,1994)$. The theory perceives interpretation as a recursive process consisting of the attribution of beliefs to speakers and meaning to sentences on the basis of the empirically observable attitude of the speakers' holding a given sentence true under given circumstances. Davidson (1973: 322ff.) exemplifies the application of PC in the form of Tarskian T-sentences:

If Kurt belongs to the German speech community then (Kurt holds true "Es regnet" at time $t$ if and only if it is raining near Kurt at time $t$ ).

Thus an English speaker can get at the meaning of "Es regnet" as equivalent to "It's raining" by observing Kurt's assent to the German sentence while it is raining and by assuming that Kurt is (characteristically) $^{2}$ not mistaken on these matters. PC thus

\footnotetext{
${ }^{1}$ Dennett refers to "assumption of rationality" which, while serving a specific theoretical function in his "intentional stance" towards belief and desire ascription, bears significant resemblance to what others theorize as PC.

${ }^{2}$ Davidson is quick to clarify that the bi-conditional is to be taken as a generalization that has to be assumed as holding true at the beginning of the process of interpretation and can later be defeated when more data are gathered and broader understanding of the foreign language is achieved (see Davidson 1973: 323, and below).
} 
works together with empirical data to methodically reach basic understanding:

This method is intended to solve the problem of the interdependence of belief and meaning by holding belief constant as far as possible while solving for the meaning. This is accomplished by assigning truth conditions to alien sentences that make native speakers right as often as plausibly possible, according, of course, to our own view of what is right. What justifies the procedure is the fact that disagreement and agreement alike are intelligible only against a background of massive agreement. (Davidson 1973: 324)

So construed, the charitable assumption of truth does the trick of gluing radical interpretation where the basic elements (meaning/truth conditions, belief) are prone to fall apart. Therefore, Davidson gives the principle a pivotal place in his procedure. It is a condition sine qua non of understanding, understood as rational interpretation: "all successful interpretation depends upon the application of the principle of charity" (Davidson 1994: 122).

Davidson's formulation has been considered as including highly controversial claims, such as "make native speakers right as often as plausibly possible" (Davidson 1973: 324). It has been argued that so conceived, the principle may blind us against other speakers' obvious lapses in rationality by eliminating the possibility of attributing a false or inconsistent belief to them. Thagard and Nisbett (1983) and Levin (1988), for instance, bring to bear results of famous experimental studies of Kahneman and Tversky that expose systematic weaknesses in human inferential capabilities. On a daily basis, people tend to rely on simplified cognitive heuristics, which often lead to egregious mistakes in reasoning. Yet, PC directs us toward interpreting them as right and reasonable. The problem opens up the question of one of the notorious "paradoxes of irrationality" (Davidson 1982/2004; Henderson 1987b): how to attribute irrationality in the process of interpretation governed by PC that dictates the attribution of rationality?

Indeed, Davidson speaks of the possibility of the speakers' being mistaken as the first "obvious objection" to PC (Davidson 1973: 323). Making "speakers right as often as plausibly possible" (op. cit.: 324) excludes implausible attributions of truth and is subject to revisions in the process: "The methodological advice to interpret in a way that optimizes agreement should not be conceived as resting on a charitable assumption about human intelligence that may turn out to be false" (Ibidem). Therefore: 
The method is not designed to eliminate disagreement, nor can it: its purpose is to make meaningful disagreement possible, and this depends entirely on a foundation-some foundation-in agreement. [...] Charity is forced on us; - whether we like it or not, if we want to understand others, we must count them right in most matters. We make maximum sense of the words and thoughts of others when we interpret in a way that optimizes agreement (this includes room, as we said, for explicable error, i.e. differences of opinion). (Davidson 1974: 19)

The notion of error, and even more so of "explicable error," clearly presupposes an idea, perhaps a whole theory, of correctness; after all "irrationality is a failure within the house of reason" (Davidson 1982/2004: 169). On this account, PC is not an impediment to, but rather a condition of the possibility for, detecting errors. ${ }^{3}$

This is not to say that some serious criticisms cannot be justifiably leveled against other (less charitable?) interpretations of Davidson's principle of charity, or against interpretations of the principle other than Davidson's (Quine's, Lewis's, Dennett's). Indeed, much of the criticism has been directed again some derivatives of the principle, such as used in cognitive psychology, decision theory, or even political science (Levin 1988; Thagaard \& Nissbet 1983). But such derivatives, formulated in a context very different from Davidson's and thus serving very different theoretical functions, should not receive a uniform treatment. A combination of various conceptual aspects under the same label can easily lead to absurdities, such as the purported impossibility of attributing unreasonable belief to evidently mistaken speakers.

To briefly summarize: The principle of charity has been introduced by philosophers of language, notably Davidson, as a systematic, theoretically-derived condition of possibility for an idealized process of meaning and belief attribution. The idealization involves the assumption that interpretation is in fact a rational interpretation that should in principle deliver a set of rational beliefs that are largely correct and coherent. In the process, an interpreter applies the principle in order to understand a speaker, at least up to a level of establishing enough common

\footnotetext{
${ }^{3}$ There has been a continuous and lively discussion regarding the precise status of Davidson's principle. Some see it as a non-empirical, a priori conceptual truth, or a constitutive principle of belief and meaning ascription (as opposed to a merely regulative maxim of good interpretation) (Vahid 2010), others as an empirically-grounded, a posteriori necessity of "psychologiconomological kind" (Glüer 2006; Pagin 2006; see also Fodor \& Lepore 1994; Glauker 1986; Henderson 1987a, 1987b).
} 
ground for some further more refined modes of communication that may include empirically warranted attribution of error and discussion of differences of opinion. This point seems crucial in the proper appreciation of the derivative of the principle used in a dialectically-oriented argumentation theory where disagreement is inscribed in the procedure for a rational weighing of pros and cons.

Following philosophers' discussions in the 1960's and 1970's, argumentation scholars reformulated PC specifically for the purpose of interpreting argumentative discourse. The classic account of PC in argumentation theory was formulated by Scriven:

The Principle of Charity requires that we try to make the best, rather than the worst, possible interpretation of the material we're studying. That is, even if, as a matter of strict grammar, we could shoot the writer down for having said something that doesn't follow or isn't strictly true, it may be more charitable to reinterpret the passage slightly in order to make more "sense" out of it, that is, to make it mean something that a sensible person would be more likely to have meant. [...] [The Principle] tells you that you want to interpret the argument's meaning in whatever makes the most sense and force out of it, because otherwise, it can easily be reformulated slightly in order to meet your objections. That's why it is a sound practical advice. (Scriven 1976: 71-72, italics original)

By framing the principle in terms of "sound practical advice", Scriven clearly abandons the philosophical inquiry into the conditions of meaning determination. The rationale behind applying the principle is, instead, ethical and prudential: less-thancharitable interpretations violate the requirement to "be fair or just in your criticisms" (Scriven 1976: 71) and, moreover, can easily be rebutted in a discussion. According to Johnson (1981), PC plays an important role in identifying and reconstructing arguments, identifying the missing premises of enthymematic argumentation, and criticizing arguments. All these applications are meant to give the analyzed arguer the benefit of the doubt; a critic's analysis and evaluation should address the strongest plausible interpretation of a given piece of argumentation. ${ }^{4}$

Since it is not a goal of this paper to revise and resuscitate the extended debate over PC in argumentation theory, I will sketch this debate following what seem to be its three main results: (1) some kind of basic charity is necessary and unavoid-

\footnotetext{
${ }^{4}$ See below (section 3 ) for the different senses in which "the strongest (plausible) interpretation" can be understood as a charitable interpretation.
} 
able in argument analysis and evaluation; however (2) strong charity (as typified by Scriven's formulation) is methodologically and practically unsustainable; therefore (3) some limited, modest, or moderate charity should instead be adopted.

(1) The goal of argument analysis is a detailed, carefully and methodically conducted interpretation and reconstruction of argumentative discourse. Only following such an analysis, is an adequate evaluation of discourse according to an adopted standard of argumentative rationality possible. Since, as famously argued by Quine (1960), interpretation of language is characteristically underdetermined, argumentation analysts may face a familiar situation in which a piece of discourse can, in one and the same context, leave the room for competing plausible interpretations. This is exactly where PC should find its application in argumentation theory (Govier 1981, 1982, 1987; Snoeck Henkemans 1992). PC thus functions as a lifebelt in emergency situations in which the analyst is lost in the maze of "equally licensed" interpretations (Govier 1981). S/he should pick the primus inter pares, that is, the interpretation "which generates the most plausible argument" (Govier 1987: 148).

(2) While Scriven pleads that charity should not mean "letting people off the hook entirely by assuming they couldn't possibly have meant something just because it turns out to be untrue or unsound" (1976: 71), he clearly allows for "slight reformulations" of the original argument meant to save its reasonableness. Such an application may, however, put us on a slippery slope. Johnson, referring to passages from Scriven, argues the following:

[...] it seems to me that we have gone beyond the bounds of charity here. Why should we delete or overlook specious reasoning simply because it seems obviously specious? [...] There must be some room to maneuver here between, on the one hand, cheap shots and nitpicking, and, on the other hand, just ignoring blatantly poor reasoning. Benefit of the doubt, si; whitewash, no! [...] This is not charity; it is welfare! This is no longer argument analysis and criticism; it is argument construction, taking the skeleton provided by someone else and expecting the critic to provide the flesh and blood. (Johnson 1981: 8)

Similarly, Govier (1982, 1987) convincingly argues that "strong" charity proposed by Scriven must not override basic requirements of "truistic" charity, that is, of a careful, attentive interpretation of naturally occurring discourse with all its contextually-determined nuances of meaning (irony, qualifications, 
presuppositions). In other words, empirical considerations should always be given priority over the theoretically-derived presumption of reasonableness. Other reasons for renouncing a strong PC in argumentation theory have also been given, in particular in its crucial area of implementation, that of reconstructing the missing (suppressed, hidden, implicit, unexpressed) premises in an enthymeme (Bermejo-Luque 2010: 179ff.; Gough \& Tindale 1985; Johnson 1981; Paglieri \& Woods 2011a, 2011b; Walton 2000; Walton \& Reed 2005). Walton and Reed contend that widespread application of PC in enthymeme reconstruction typically leads to a straw man fallacy of sorts, since a charitable interpreter attributes to an arguer a premise that $\mathrm{s} /$ he did not actually endorse. Paglieri and Woods argue that PC's functions are either fully reducible to or at least severely constrained by the basic principle of cognitive parsimony and its corollaries such as (semantic and inferential) familiarity (see also Gauker 1986).

(3) Still, critics of PC contend that despite all such objections it should not be abandoned. A slight reinterpretation of charity can fulfill the need for a methodical guideline in case of interpretive doubt ( 1 above), while guarding against the most obvious criticisms ( 2 above). One possibility of salvaging PC is to limit the scope of its applicability to cases of "(i) a fully expressed argument (ii) from a serious arguer (iii) on a serious matter" (Johnson 1981: 8). This circumscription of PC obviates the problems involved in enthymeme reconstruction and pictures argumentation in terms of a serious, co-operative activity, where "cheap shots" of both the arguer and interpreter are excluded. Govier, similarly, endorses a view of argumentation as a form of rational communicative action governed by co-operative presumptions as defined by Grice (see also Walton 2000). While noticing the importance of disagreement in argumentation, Govier stresses the element of rational co-operation that in her view is crucial to a proper assessment of PC:

We presume that others who participate in the practise of argument and rational discussion intend to convey sensible claims and to support these claims with well-reasoned arguments. That is to say, they regard their beliefs and arguments as sound; we may or may not. We do not have to agree to understand. The charity that emerges is moderate charity. (Govier 1987: 151-152)

Thus, our engagement in argumentative interactions, including interpretation, presumes some basic rules and rational standards that justify the expectation of reasonableness. Yet, an argumen- 
tative discussion would not start off if not for some form of disagreement or at least doubt over the professed thesis (or a set of theses). That is to say, arguers are engaged in what may be called a co-operative contest (see Aristotle's koinon agon). That brings us to a dialectical perspective, in which argumentation is seen as a rational and critical discussion where sensible claims and arguments are expected to be offered, but also critically scrutinized. Looked at from this point of view, while greatly informative, all the accounts of PC described above fail to appreciate the basic tenets of dialectical argumentation.

Based on this brief introduction one can easily point out at least three important differences between the theoretical functions given PC in philosophy of language and argumentation theory. ${ }^{5}$ To start with, the reasons for interpretive troubles that call for the application of $\mathrm{PC}$ are distinct, if not in kind, then at least in scale. While philosophers focus on basic problems of understanding, such as getting at the meaning of new or foreign expressions and the mental states that accompany them, argumentation theorists resort to PC to reconstruct arguments from a familiar and well-understood language used in a given instance in a vague, ambiguous, or incomplete manner. Therefore, secondly, while the philosophical conception of PC is expounded as a necessary condition for basic understanding, the argumentative notion enters the stage only after basic understanding is firmly secured. Argumentation, as opposed to explanation, employs reasoning in a situation of mutual understanding, but lack of agreement. As argued above (see also Adler 1994, 1996), such intelligible disagreement is perfectly reconcilable with, if not conditioned by, the application of PC in the philosophical sense. Govier sums this point up nicely when she claims that on Scriven-type accounts:

[...] charity is seen as an option at the practical level, rather than a broadly theoretical necessity. To fail to employ strong or moderate charity would not be to lose our grip on understanding altogether, but rather (it is alleged) to do something unethical, imprudent, or epistemically inefficient. (Govier 1987: 143)

Although she takes issue with Scriven's account, Govier clearly identifies the possible source of confusion between two notions of PC as an inconspicuous conceptual step from the realm of understanding and interpretation to the realm of reconstruction and evaluation of argumentative discourse.

\footnotetext{
${ }^{5}$ See Adler (1996) and Govier (1987) for a fuller discussion. My exposition differs, to varying degrees, from both these accounts.
} 


\section{Marcin Lewiński}

Finally, argumentation theory in its widely recognized pragmatic (following Austin 1962) and dialectical (following Hamblin 1970) formulations is chiefly concerned with the (external) commitment attribution (van Eemeren \& Grootendorst 2004; Walton \& Krabbe 1995), rather than the attribution of internal mental states (beliefs, desires, intentions). That is to say, PC is applied in the practical task of determining the set of externalized, publicly accessible commitments that an arguer is expected to defend and be criticized for according to the burden of proof appropriate for a given argumentative encounter. This is quite different from philosophical attempts to construct concepts instrumental in understanding the mental states expected to motivate or accompany utterances (and other actions) of rational human agents. An important theoretical justification for this shift lies in a certain practical limitation: we have unmediated insight only into expressed commitments, and not into internal mental states. Therefore, trying to chase "the real position" of an arguer, what "the arguer really just means," or "what the arguer's argument really is,", is a methodologically suspicious undertaking, as the only source of our insight into the mental states of an arguer will be the arguer him/herself. And leaving the judgment to the subject to be judged is not a robust methodology.

One crucial similarity with the philosophical treatment has to be mentioned too. PC in its strong, Scriven-type formulations, may lead to a problem of attributing fallaciousness; it seems hard, if not paradoxical, to attribute serious lapses of reasoning

\footnotetext{
${ }^{6}$ As suggested by one of the reviewers.

${ }^{7}$ I assume that the ultimate goal of an argument analyst is a methodic critique of "real-life" argumentations - a thesis uncontroversial across argumentation theory. From the perspective of this task, imagine an arguer A who puts forth an argument $x$, deemed to be ambiguous by her fellow discussants. One critic of A suggests that under a plausible interpretation $x_{l}$, A's argument can be easily refuted. A is not sure how to clarify $x$ which she believed to be "wellformulated" and "self-understanding", and defends herself with an impromptu and possibly still vague interpretation $x_{2}$. As she does so, some other discussant volunteers interpretation $x_{3}$, which is also plausible, but makes the argument cogent. A replies "Yes, this is what I was trying to say; I simply didn't manage to put it so elegantly..." What is "the arguer's real position" here: $x, x_{1}, x_{2}$, or $x_{3}$ ? By giving up the project of reconstructing "the actual," "the real" beliefs-desires-intentions, we move to a humbler task of attributing (and subsequently evaluating) argumentative commitments. Here, we should decide between vague $x$, uncharitable (because it refutes the argument) $x_{1}$, improvised and still vague $x_{2}$, or charitable $x_{3}$. Each of them has its merits: $x$ are the actual words, $x_{1}$ supports a falsificationist methodology, $x_{2}$ is the first take at clarification by the arguer herself, $x_{3}$ makes the best out of the case. PC plays a role in deciding on the hierarchy of these merits - and further along I argue that in a dialectical analysis of discussions this should rely on contextual considerations.
} 
in our interpretation of other arguers while applying reasonableness-presuming $\mathrm{PC}^{8}$

\section{The paradox of charity in the dialectical analysis of ar- gumentation}

Rather than deepening the previous criticisms of the ways PC is applied in argumentation theory, most of them relevant and well-founded, I will go sideways to explore a new way of problematizing the application of PC in a dialectical analysis and evaluation of argumentation. Let us start from the following, tentative formulation of the principle:

In case of interpretive doubt, one should apply the principle of charity by crediting an arguer with the strongest plausible interpretation of her discourse.

While relatively uncontroversial, this definition of PC contains at least three elements that require clarification:

1. What does "the strongest plausible" interpretation exactly mean?

2. Who exactly should apply PC?

3. Who exactly should be credited with charity?

To begin with, the very notion of "the strongest plausible" interpretation can itself receive at least two plausible interpretations. One of them is Adler's proposal to understand it as "a stronger statement of the argument", that is, a more extreme formulation of the argument, since this allows for a more "severe test" of falsification (1982: 16). The other is to take it as the interpretation "that is most likely to be successfully defended by the arguer" (Snoeck Henkemans 1992: 104, italics original). Take for example a vague argument: "I wouldn't go out with him, because mathematicians are so boring". On the former reading the strongest interpretation would disambiguate it to "all mathematicians are boring", on the latter most probably to "some mathematicians are boring". It seems reasonable to treat as charitable the latter understanding of "the strongest" interpretation, since it lets the argument withstand more criticisms. However, this im-

\footnotetext{
${ }^{8}$ This has been the main theme in Adler's $(1994,1996)$ study. Without explicit recourse to the crucial differences between philosophical and argumentation theoretical treatment of PC that I mention above, Adler has convincingly argued that it is not a paradox to govern our interpretations by PC (in the philosophical sense) and engage in serious argumentation criticism that involves fallacy attribution.
} 


\section{Marcin Lewiński}

mediately brings out another problem: even assuming that "the strongest plausible" interpretation amounts to "the most easily defensible," one can still distinguish between:

(A) The conventionally most obvious interpretation of the propositional content of the premise in question. For instance, "some people" used in ordinary contexts will most plausibly be interpreted as "more than two, but not all people" (Levinson 2000). Similarly, "Don't trust him, he's a liar" most plausibly refers to a "habitual liar." Note that while most easily defensible following pragmatic conventions of ordinary language, such interpretations are uncharitable in an argumentative sense, since they attribute more than minimal commitments to an arguer. This may lead to accusations of the straw man fallacy (Lewiński 2011).

(B) The argumentatively most easily defensible propositional content of the premise in question. Therefore, "some people" can be given a plausible logical interpretation of "one person or more" and "liar" can minimally denote an "incidental liar." In these cases, just one person or one instance of lying are enough for the proposition to stand as acceptable. Hence, the plausible does amount to the charitable, but only in the isolated sense of charity covering a single premise. Such a charitably interpreted individual premise may, however, function as an element of rather weak argumentation. "Liar" interpreted as "incidental liar" may very well save the proposition itself, but does not carry a strong argumentative force: "Don't trust him, he once lied in the past" is far from a cogent piece of argumentation. Therefore, finally, one should consider:

(C) The interpretation that makes the whole premise-premiseconclusion complex most easily defensible. This option, in a sense, takes us back to (A), since "Don't trust him, he's a habitual liar" is overall much more plausible an argument than "Don't trust him, he once lied in the past," even though the very content of the premise requires more evidential support. We can thus identify here a well-known trade-off in argumentation: the obviously defensible (strong, plausible, charitable) interpretation of the propositional content of a premise may leave the whole argumentation weak, trivial, indeed implausible, since it points to a very weak argument scheme (e.g., "Never trust people who once lied"). Conversely, the most easily defensible interpretation of the entire argumentation may require attribution of individual premises that carry high burden of factual proof (e.g., "He lied quite a few times, so don't trust him"). 
Mindful of these underexplored complications in defining "the strongest plausible" interpretation, I will go on discussing the problem that I dub the paradox of charity that may arise irrespective of which of these possible definitions of plausibility is ultimately adopted. The exposition of the paradox rests on addressing the two remaining questions mentioned above: Who should actually apply PC (who is the expected benefactor)? Who should be credited with charity (who is the beneficiary)? These questions seem trivial, but under scrutiny they expose some crucial ambiguities. Regarding the first question, two options seem pertinent:

(1) an arguer facing another arguer (an antagonist facing a protagonist)

(2) an analyst assessing an arguer's discourse (external judge)

Of course, ideally each arguer is also an attentive and perhaps well-trained analyst of argumentation, and each analyst should be able to engage as a party in an actual argumentative discussion. Thus they can become one and the same person-a possibility inscribed in the capacious, if not equivocal, notion of argumentation "critic" (critic as antagonist vs. critic as critical analyst). Typically, however, actual arguers engaged in their disputes have little chances of acting as trained and impartial analysts of reasoning and argumentation, similarly to plaintiffs and accused who hardly have the comfort of becoming the adjudicating judges. Moreover, as I will be showing below, the import of applying PC to either the antagonist or the analyst is clearly different. Let me look at these two options in turn.

\subsection{An arguer interprets another arguer}

The situation in which arguers interpret each other's discourse in an argumentative discussion looks more or less like this:

\section{(naïve) \\ interpretation}

Protagonist

Antagonist

This seems to be the background of Scriven's formulation of PC. When he talks about "sound practical advice" regarding "fair criticisms" and about not "letting people off the hook" (Scriven 1976: 71ff), he clearly envisions PC as having a status of a rule for good counter-argumentation, which should be 
followed by ordinary critics-as-antagonists in order to preserve the reasonableness of their disputes. But should it be?

A situation to which Scriven refers is par excellence dialectical. An arguer presents a piece of reasoning for a conclusion not as a standalone, isolated artifact (such as, for instance, a mathematical proof), but rather as a contribution to a dispute. Therefore, the reasoner is expected to face doubt or challenge leading to objections and counter-argumentation. Further, she has an option to rebut criticisms, for instance those that unfairly interpret her discourse in a less-than-charitable manner; thus, she engages in a straightforward dialectical encounter with another arguer. As typically theorized (Barth \& Krabbe 1982; van Eemeren \& Grootendorst 2004; Walton \& Krabbe 1995), such an encounter amounts to a contest of opinions in which - apart from joint benefits of examining the veracity of a claim or deciding on a prudent course of actionindividual victory or loss are at stake. The benefit to "the loser" of a dialectical encounter is to realize that some claim other than her initial position is preferable on the (rational) grounds she herself adhered to. ("The winner," of course, gets it all.) But until this realization, the possible loser is expected to seriously engage in a joint examination by means of defending her position (and contradicting the other position) as much as possible; otherwise the very results of the dialectical examination may be distorted. That is because, according to Aristotle, "conceding at first what one should not [an erroneous thesis-ML] is probably a different mistake from failing to defend this concession properly" (Topics: 159a 23-25). Hence:

[...] at the end of the disputation, regardless of whether there is a winner or not, the two contenders will be also judged with respect to the way in which they have conducted their argumentations, so that one can end up being a good loser, in which case the fault will not be with him but with the thesis. (Spranzi 2011: 30) ${ }^{9}$

Under such circumstances, giving a deliberate advantage to an opponent by being charitable characteristically goes against the

\footnotetext{
${ }^{9}$ Poor defense and attack may lead to abandoning a strong thesis or accepting an unwarranted one. Analysts of Aristotelian dialectic notice that one crucial consequence of viewing dialectic as an activity in which the common goal (critical examination of a thesis) is achieved by a regulated clash of individual goals (to win the dispute) is that the distinction between collaborative, examination-based "peirastic" dialectic and the competitive, "agonistic" dialectic collapses: "peirastic" outcomes result from "good agonistic" practices (Spranzi 2011: Ch. 1; see also Krabbe 2009). For Johnson, in dialectic "the interests of the arguer and the critic converge around strong criticism that most serves the cause of manifest rationality" (2000: 243).
} 
individual goal of winning the contest. Moreover, it may seriously skew the joint examination of the (doubted or challenged) thesis: we may gentlemanly overlook plausible interpretations that invalidate the examined claim and end up "ignoring blatantly poor reasoning" (Johnson 1981: 8).

A contemporary account of dialectical argumentation as a collaborative competition is provided in the extended pragmadialectical theory of argumentation (van Eemeren 2010; see Krabbe 2009). In a critical discussion, the antagonist's dialectical task is to react critically against the protagonist's position in order to mount as thorough as possible attempts at its falsification. Such attempts are paramount of a dialectical critical testing that embodies an epistemically justifiable form of rationality (van Eemeren \& Grootendorst 1988). If these attempts are to be efficient, the antagonist, in his (reasonable) strategic maneuvering (van Eemeren 2010) against the protagonist, should follow what I term the strategy of the easiest objection. By this strategy, the antagonist should first react critically to those elements in the protagonist's argumentation that are prima facie most easily refutable. ${ }^{10}$ Why bother objecting to the presumably defensible elements, when, for instance, the protagonist's complex argumentation hangs on a little false premise or a weak inference. It seems only reasonable to start a critical check-up of the other's argumentation from the most suspicious elements just as much as it is reasonable to make a move on a chessboard that targets the supposedly weakest point of the opponent's strategy. ${ }^{11}$ The obvious limitation is that both parties, while engaged in a contest, have to play by the rules.

Because of the problems in straightforwardly defining charity through interpretive plausibility, an arguer can play by the rules by proposing interpretations that are contextually plausible in one of the senses distinguished above, but not necessar-

\footnotetext{
${ }^{10}$ As an alternative, the antagonist may resort to the strategy of the most damaging objection which targets the weakest element of criticized argumentation, even if it requires a deeper scrutiny and more effort to show that the element in question is indeed flawed. In favorable circumstances, both strategies go hand in hand (cf. an evident checkmate in chess); if they do not, an arguer should be free to opt either for a first easy shot (perhaps it suffices?) or for a subtly crafted significant blow. Importantly, my argument applies to both these strategic choices. (I thank an anonymous reviewer for suggesting this distinction.)

${ }^{11} \mathrm{Cf}$. Walton and Reed who expound a rationale for applying PC on pragmadialectical grounds: "To make the critical discussion successful, each party should put forward the strongest and most convincing arguments possible to support his or her thesis. This aspect seems to support the principle of charity" (2005: 364). Interestingly, this argument mentions only support of a thesis, glossing over the criticisms that are the fundamental aspect of what is a critical discussion.
} 


\section{Marcin Lewiński}

ily charitable. Such interpretive choices may be seen as instances of applying the strategy of the easiest objection in an arguer-to-arguer interpretation (or naïve reconstruction, see van Eemeren et al. 1993: Ch. 5). I will further illustrate difficulties inherent in the expectation of charity in a short example.

Imagine a group of graduate students meeting on Monday discussing their weekend activities:

A: How was the weekend? Did you manage to get into the sold-out gig you were so eager to see?

B: It wasn't that bad...

A: Oh, really?! I heard it was a disaster...

B: Not at all. Some of us managed to get a ticket!

A: "Some", that is, how many? All of you? Most of you? You and Katie? Or just you?!

On an argumentative reading, B defends his position ("the weekend wasn't that bad") by means of a single argument ("some of us managed to get a ticket"). Characteristically for a natural language argumentation, the argument is not fully precise. What does "some" mean? As mentioned above, the most usual, indeed most plausible, understanding of "some" is "more than two, but not all" (by the so called scalar implicature, see Levinson 2000). So, on this "most plausible interpretation," the argument would hold only if three or more friends got into the venue. However, one should not exclude as plausible the strict logical reading of "some" in terms of an existential quantifier: some = "one or more" ("at least one"). Assuming additionally that the speakers are young analytic philosophers, there is nothing terribly odd in reading "some" as "one," even if it surely is not "the most plausible" conventional interpretation. It is however the most charitable one in the sense of defensibility of the explicit premise on which the argumentation rests: it is enough for B to have evidence of getting one ticket to defend his argument.

Assuming that the strength of B's argumentation indeed hinges on the acceptability of the factual premise in question, it is hard to see a reason why an arguer disputing B's claim should take "one" as the best interpretation of "some" by principle; yet that is exactly what PC does in this situation. On the other hand, of course, taking "some" to mean "most" or "many" seems not only uncharitable but also implausible in most typical contexts. ${ }^{12}$ So these interpretations are excluded by lacking contextual plau-

\footnotetext{
${ }^{12}$ Some unusual contexts can always be envisaged. Imagine that B represents a group of three. If "some" is at all usable for such a group, then either some $=$ one or some $=$ most of us.
} 
sibility, not charity. However, nothing seems to prevent a reasonable arguer involved in a critical dialectical examination from strategically picking the level of plausibility (for instance conventional pragmatic plausibility of "some" as "more than two but not all") that would make for the easiest, potentially most successful, objection. ${ }^{13}$ For such reasons, there is something fishy in requiring that arguers themselves apply PC. Here, a dialectical view on argumentation is in agreement with a pretheoretical linguistic intuition: charity, ordinarily understood, rests on a free choice, rather than a principled obligation.

\subsection{An analyst methodically interprets an arguer}

Johnson, Govier, Walton, and others may, however, have had a different use of PC in their minds. Johnson, for one, clearly claims that it is "the heavy artillery of argument analysis," not a naïve arguer-to-arguer interpretation, that is "monitored by the requirements of the Principle of Charity" (1981: 8). He thus repeatedly uses the notion of a "critic" in the sense of an analyst who, for instance, "select[s] fallacy theory as the matrix of informal analysis" (op. cit.: 7). Similarly, Govier (1987: 141ff.) envisages the applications of PC in six "stages of argument interpretation" that are methodical steps a trained argument analyst is expected to take before passing a theoretically justified judgment on the soundness of argument. Following such an account, we get a rather different picture of the situation in which PC applies:

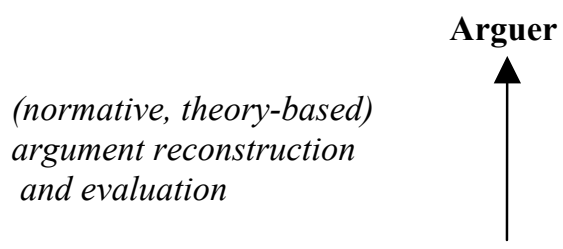

\section{Argumentation analyst}

From this perspective, the use of PC is required of an argumentation analyst who applies his theory-based methods of normative reconstruction (van Eemeren et al. 1993: Chs. 3 and 5) to (what seems to be) monological discourse. PC thus supports a classic task of (informal) logic: a keen-eyed analyst is

\footnotetext{
${ }^{13}$ As noted above, the unexpressed linking premise (e.g. "if one of us gets a ticket, it's a good weekend") may be further objected to. In this case, A's uncharitable insistence on discarding "some" as "one" may be additionally justified on the grounds that the more plausible commitment "a significant number of us have to get a ticket for it to count as a good weekend" should be kept.
} 
out to check if the reasoning is correct, that is, if all the inferential chains of a single reasoning subject (a speaker, an arguer, the protagonist) are in fact sound relative to some ideal standards (deductive, inductive, abductive, presumptive, etc.). But then again, this is not how any of the afore-mentioned exponents of PC thinks of argumentation; rather, they picture a dialectical contest, where there are two, not just one, arguers to interpret and evaluate. $^{14}$

If the monological scheme seems too simplistic, one can resort to a trick of grasping the role of a "critic" in its possibly dual function and (charitably) allow for flexible shifts between critic qua analyst and critic qua antagonist. ${ }^{15}$ However, saying that a critical analyst's work entails a dialectical engagement turns any logician into a dialectician. Logicians and dialecticians alike may be compelled to object. Or else, an analyst facing the task of interpreting and evaluating an argumentative discussion, where two parties clash, may scrutinize the protagonist's and the antagonist's lines of reasoning one by one. This, however, generates the problem of weighing each of the side's arguments - a difficult task, since: (1) they both may be based on valid reasoning and differ only in the adopted starting points, whose evaluation characteristically extends the competence of argumentation theory (Lewiński 2012) and (2) the arguers may (indeed should) include in their (counter-) reasoning parts of the other party's arguments; and this requires some form of interpretation that typically, as argued above, cannot be expected to be charitable.

If this analysis is correct, both interpretations of the addressee of PC (the benefactor of charity) — critic as arguer and

\footnotetext{
${ }^{14}$ One of the reviewers suggested that while the informal logicians mentioned here "have emphasized a need to consider dialectical approaches to argument to varying degrees [...] it is easy to interpret their appeal to PC as applying in monological cases". That would mean, using Johnson's (2000) terminology, that PC is used (exclusively?) in the examination of the illative core of argumentation, but perhaps suspended in the analysis and evaluation of the dialectical tier. This interesting limitation of the scope of application of PC would of course invalidate my reservations here. However, unaware of an explicit conceptualization of such a limited principle, I continue my discussion. (For Johnson at least, it is precisely in the dialectical tier that PC will be most applicable as one of the principles of criticism (2000: Ch. 8).)

${ }^{15}$ This is clearly suggested in Walton's account of PC within the "new dialectical rules for ambiguity": "These rules are shown to be conversational (dialectical) in nature. They presume a framework in which the critic is engaged in a kind of collaborative dialogue with the proponent whose argument is being criticized. In typical cases dealt with in informal logic, the proponent is not present to defend his argument, or say what she meant. But the ten rules are based on a kind of meta-dialectical assumption that the relation between critic and arguer can be seen as a kind of collaborative conversational interaction" (Walton 2000: 262).
} 
critic as analyst - lead us, in one way or another, to a dead end, albeit in the same dialectical neighborhood. That is why I turn now to a third option that seems obvious in a dialectically oriented argumentation theory but has somehow failed to draw the attention of argumentation philanthropists.

\title{
3.3 An analyst methodically interprets arguers involved in a dialectical discussion
}

The final possibility is one in which PC is a methodological principle directed to an analyst who interprets (and subsequently evaluates) dialogically constituted argumentative discourse (this includes both explicit and implicit dialogue; see Blair 1998 and Lewiński 2012). One clear formulation of such a function of PC is given by Snoeck Henkemans:

\begin{abstract}
When an utterance is analysed in the context of a discussion aimed at resolving a dispute, the analyst should not just check whether his interpretation is plausible in the light of pragma-linguistic conventions, but he should also make sure that this is the interpretation of the utterance that is most likely to be successfully defended by the arguer. Only if the latter is ensured is his interpretation, seen from a pragma-dialectical perspective, the most charitable. (Snoeck Henkemans 1992: 104, italics original)
\end{abstract}

This formulation clarifies two important points. First, PC is to be applied by an analyst in his normative, theory-driven reconstruction of argumentation, rather than by the arguers themselves in an on-going process of pre-theoretical naïve interpretation. Second, PC pertains to a reconstruction "in the context of a discussion aimed at resolving a dispute," that is, in the pragmadialectical theory, a critical discussion between the protagonist and antagonist (van Eemeren \& Grootendorst 2004).

Following such an account, the situation of an argumentation analyst, who has the task of reconstructing and evaluating contributions to an ordinary dispute that include both the protagonist's arguments and the antagonist's critical reactions, looks more or less like the scheme below.

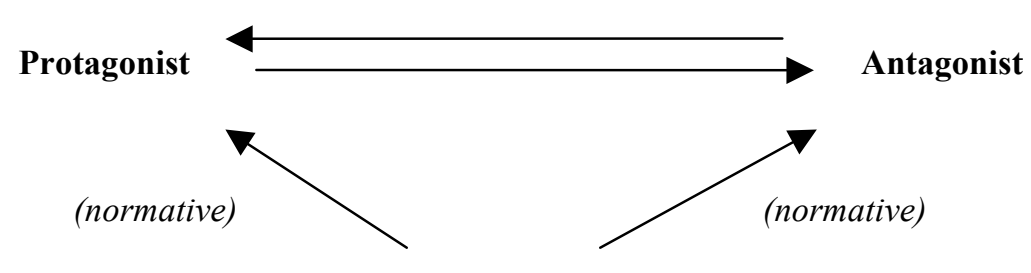




\section{Argumentation analyst}

This simple scheme seems rather obvious, but it reveals the paradox of charity that poses a significant challenge to a consistent application of PC in a dialectical analysis and evaluation of argumentation.

The "naïve" protagonist $v s$. antagonist interpretation in a dialectical situation should proceed as described above: both of them are required to rely on contextually plausible interpretations and allowed to resort to the strategy of the easiest objection. Hence, in the example used above ("the weekend wasn't that bad because some of us managed to get a ticket"), the protagonist (B) may try to enforce the "some = one or more" interpretation, while the antagonist (A) the "some = three or more" interpretation. In this way, unless they manage to iron out a mutually shared interpretation through some form of an "intersubjective interpretation procedure" (Lewiński 2011: 483484), the arguers can easily reach an interpretive deadlock. Provided that, as argued before, charity is for them an interpretive choice, rather than a principle that must be followed, a resolution of the deadlock (in terms of deciding whose case holds) becomes the analyst's prerogative.

An argumentation analyst's position in the normative reconstruction of the protagonist's and the antagonist's expressions is quite different from that of the arguers. In the approaches discussed above, an analyst's task is to systematically reconstruct all the commitments of an arguer by applying precisely defined concepts of argumentation theory and following certain theoretically stipulated guidelines, such as (moderate) PC: if a given formulation of a standpoint or argument allows for many interpretive options, and neither contextual considerations nor background knowledge indicate a solution, then an analyst should take that option which is most charitable to the arguer. In the case of a normative reconstruction of the protagonist's contributions, the reconstructed commitments should be the ones s/he can defend most easily. This is where the description of PC typically ends. But it seems only reasonable to add the obviously overlooked converse application, in which a charitable reconstruction of the antagonist's part should follow the path of the strongest plausible criticism, in which case the commitments of the defendant are more extensively problematized. That is to say, not only can an analyst credit the protagonist with the strongest justificatory interpretation but also the antagonist with the strongest refutatory interpretation of a vague, incomplete, 
imprecise, or otherwise interpretively contested claim.

In this kind of a situation, an argumentation analyst engaged in normative reconstruction faces a dilemma that ultimately leads to a paradox. Whenever there is insurmountable doubt regarding an interpretation of a standpoint or argument, and arguers themselves are in disagreement over their naïve interpretations (both of which seem plausible, one way or another), should the analyst be charitable with the protagonist's or the antagonist's interpretation? That is to say, in making certain interpretive decisions an analyst faces a dilemma of taking sides: should s/he favor the protagonist's building up the strongest plausible defense or the antagonist's launching the severest attack? Does "some" refer to "one or more" or "three or more"? Furthermore, once the analyst decides to take one of the sides, s/he faces an interpretive paradox: by being charitable to one arguer, the protagonist, $\mathrm{s} / \mathrm{he}$ is uncharitable to another arguer, the antagonist; and the other way round.

To clearly characterize the paradox I will follow Rescher's (2001) framework for paradox analysis, which seems particularly relevant here. According to him, "a paradox arises when a set of individually plausible propositions is collectively inconsistent" (2001: 6, italics original). In order to resolve a paradox, one has to restore consistency of a set by abandoning some of its elements, but no more than is necessary to obtain a maximal consistent subset of the plausible propositions considered. One particularly useful way of doing it is resorting to distinctions that disambiguate some of the terms used and thus qualify their scope, eventually allowing for the set of so qualified propositions to be collectively consistent. In Rescher's view, this approach accounts for a full array of paradoxes, from mathematical, to semantic, to pragmatic ones.

The paradox of charity that is in question here seems to neatly fit into the form of a dilemma-engendered or dilemmatic paradox (Rescher 2001: 34-35). It is a practical paradox of choice and decision in which an agent is required to follow two courses of action that are mutually exclusive, as in a zero-sum game. It arises, for instance, when one is obligated to repay two different creditors $\$ 10$ each, while having, due to a theft, only $\$ 10$ left. By fulfilling one's obligation toward creditor A one is dismissing the obligation toward creditor B, and vice versa. Rescher's strategy of resolution of such paradoxes is to clearly lay out the premises of a paradox and then identify the problematic ones that can be flat-out abandoned or, more likely, disambiguated. Following his layout of the dilemmatic paradox, the paradox of charity can be elucidated in the following way: 


\section{Marcin Lewiński}

(1) By PC, one is obligated ${ }^{16}$ to be charitable to an arguer.

(2) In a competitive dialectical discussion, if one is charitable to the protagonist, one is characteristically uncharitable to the antagonist.

(3) In a competitive dialectical discussion, if one is charitable to the antagonist, one is characteristically uncharitable to the protagonist.

(4) One cannot honor all the obligations: in a competitive dialectical discussion this is impossible. (By (1)-(3).)

(5) One is required to honor all obligations.

(6) One is not required to do something one cannot possibly do.

On this reading, one is clearly both required (5) and not required (6) to be charitable to an arguer (protagonist or antagonist). Hence, we obtain the basic tapestry of any paradox: an inconsistent set of propositions (aporetic cluster), which are individually plausible (by a general principle or contextual fact). The solution is to jettison or qualify one of the propositions (1)-(3) or (5)-(6) ((4) is merely a logical derivation). In a similar case, Rescher (2001: 35) chooses (5) as a good candidate:

(5') One is required to honor all the obligations - albeit only insofar as the circumstances of the case permit (provided those circumstances are not of their own making).

This qualification would free us from the obligation to apply PC in a dialectical discussion altogether - and therefore is far from satisfying. A more fruitful way of progressing is thus to critically review the most basic premise (1). Two questions mentioned above are in need of specification here:

(1) Who is "one"? Who is the subject of the proposition? Who is to apply PC? This seems to be solved in the foregoing discussion. It is the argumentation analysts rather than just arguers themselves, who are the "ones" "obligated" to be charitable to an arguer.

(2) Who is "an arguer"? Who is the object of the proposition? Who should be credited with charity? On a dialectical account "an arguer" amounts to the protagonist or the antagonist. But there are three ways of understanding this.

\footnotetext{
${ }^{16}$ For the sake of analogy, I will follow Rescher's example of dilemmatic "obligations," while noticing, as mentioned above, that "charity" should be seen as a (commendable) "choice," rather than an "obligation" in the strict sense.
} 
a. Conjunction: an arguer $=$ both the protagonist and the antagonist. However, this exactly leads to a dilemmatic paradox in cases where competing interpretations affect the course of a discussion in the sense of a zero-sum game, since what is charitable to one arguer is uncharitable to the other. Moreover, being charitable to both the protagonist and the antagonist at the same time is typically impossible in competitive dialectical discussions. It would mean, in the case above, that B would be allowed to defend as his argument that "one or more" friends got the tickets, while A would be allowed to attack the argument that "three or more" friends did. Since each of these interpretations is plausible and charitable to one of the arguers, they follow the basic rules of normative reconstruction, and the analyst fulfills her obligations. Yet, at the same time, arguers evidently talk at cross-purposes: the defense and the attack pertain to different propositions. That means that a consistent reconstruction of the dispute between them becomes impossible; the analyst would obtain two separate discussions with two divergent (sub-) standpoints. ${ }^{17}$ We can clearly see the paradoxical structure at work here. The protagonist-charitable and the antagonist-charitable interpretations are individually plausible, but inconsistent taken together.

b. Inclusive disjunction: an arguer $=$ the protagonist or the antagonist. This option is sustainable in cases where interpretations may be charitable to both arguers at the same time. This possibility applies to instances of consensual dialectical inquiry as envisaged, for example, in Gilbert's (1997) model of coalescent argumentation. On disjunctive reading, however, being charitable to just one of the arguers still fulfills the requirements of PC. And once such partial charity becomes contestable, we move towards competitive dialectical discussions where being charitable to both arguers on the same interpretive issue is hardly attainable. This leads us to consider the last option:

c. Exclusive disjunction: an arguer $=$ either the protagonist or the antagonist. This option assumes that a competitive dialectical discussion is a zero-sum game, at least in some local contested moments where both arguers cannot benefit from interpretive charity applied to the same disputed expression. However, this

\footnotetext{
${ }^{17}$ In some cases, there may be good reasons for doing both, that is, for analyzing and evaluating a discussion both ways: what if we granted charity to the protagonist and what if we granted charity to the antagonist? For instance, would we accuse X of distorting Y's theory? If so, under which interpretive circumstances? While illuminating, this approach may stretch an analyst's resources and lead to too many counterfactual "alternative histories" of a discussion under examination.
} 
option has the potential of decisively resolving the dilemma, if there only were a principled way that would guide the analyst to apply charity to either one of the arguers in given circumstances. In the following section, I will argue for such a principled way based on contextual considerations.

Following the distinctions introduced in this section, we obtain a more precise formulation of the applicability of PC in a dialectical approach to argumentation:

The principle of charity is to be followed only in cases of interpretive doubt ${ }^{18}$ by an argumentation analyst who, depending on contextual circumstances, applies it either to the protagonist or to the antagonist by crediting one of them, respectively, with the strongest justificatory or refutatory interpretation of the discourse.

In this way, we are in a position to resolve the paradox of charity without overlooking any of its potentially problematic elements: "By merely modifying rather than outright rejecting a problematic thesis we may be enabled to give proper recognition to the full range of considerations that initially led us into contradiction" (Rescher 2001: 127). The final consideration is the exact nature of "contextual circumstances" that would resolve the paradox of charity.

\section{A possible way out of the paradox}

I hope to have made it clear in the foregoing discussion that one's approach to PC directly depends on the broader theoretical background one endorses. This applies to both philosophy and argumentation theory. In the case of the latter, a particular approach to theorizing argumentation allows for an incorporation of a particular version of PC. However, this connection is rarely explicitly discussed. Govier is a commendable exception. (Walton (2000) basically accepts and follows her account.) She clearly relates her exposition of moderate charity to Grice's theory of rational communication, on the basis of which argumentation is best understood as a cooperative communicative activity meant to tackle disagreements in a rationality-presuming fashion (Govier 1987: 148ff.). From this perspective, charity should be observed, since it supports

\footnotetext{
${ }^{18}$ As noted, this includes the lack of agreement over the interpretation between arguers themselves.
} 
rational attempts to convince in moments of interpretive doubt, but can only be moderate, since otherwise the difference of opinion between those who disagree can be underestimated or, worse still, (paternalistically) overlooked. Thus PC applies with a limited force and only to overtly rational forms of argumentation. Any form of persuasion-oriented, strategic, and thus possibly manipulative forms of argumentation exclude the applicability of PC (Govier 1987: 155-156). Hence we arrive at a conception in which we either examine rational argumentative discourse that merits moderate charity or we face strategically persuasive discourse which undercuts the rationale for implementing charity.

The pragma-dialectical concept of strategic maneuvering (van Eemeren \& Houtlosser 1999; van Eemeren 2010) takes as a point of departure for theorizing argumentation the same elements Govier uses: rational dialogue and disagreement. Yet they are differently accentuated and thus pave the way for a different appreciation of PC. Within the concept of strategic maneuvering the dialectical requirements of the ideal model of a critical discussion still safeguard a tight grip on the mutually recognized rules of reasonableness. However, the rhetorical, strategic aspect enters the stage as a legitimate, indeed indispensable, element of ordinary argumentations. Moreover, the clearly competitive spirit of most argumentative encounters can be seen as the main motivation behind actual argumentative strategies. A serious arguer is serious in that $\mathrm{s} / \mathrm{he}$ does attempt to "win" a discussion by getting the other party to accept the contested position; as a consequence, s/he would not give up her position until compelled by publicly accountable commitments. The strategies of argumentative defense and attack can therefore be expected to be conducive to reaching the goal of a successful, yet rational, persuasion of the opponent.

From such a point of view, Govier's solution verges on a false dilemma: analysts deal with either rational argumentation that merits (moderately) charitable treatment or with strategic and possibly manipulative efforts that do not deserve any charity. The concept of strategic maneuvering pictures argumentation as both rational and strategic at the same time. The consequences for applying charity are immediate: analysts can well entertain no charity despite the presumed rationality of discussions, just as much as they can be charitable even assuming the strategic nature of arguments. How does that work? And does that help solving the paradox of charity in any way?

First, I would like to argue for a fairly minimal role for PC in argumentation theory, and minimal in a few respects. The principle should clearly be addressed to analysts of 
argumentation rather than arguers themselves. If argumentative discussions, at least in certain contexts or parts, are seen as competitive exchanges, then charity can be nothing more than a strategic option for arguers, perhaps only under special circumstances. (Think of a powerful strategy whereby a confident arguer easily rebuts her opponent's arguments, even though she follows a charitable interpretation.) Argumentation analysts should focus their attention on textual and contextual empirical data as much as possible, so that situations of interpretive doubt arise as seldom as possible. Once they do arise, an analyst should verify if there is an interpretation of an ambiguous term that both parties can agree on. ${ }^{19}$ If the parties are not able to agree (for instance they are not available for mutual consultation, such as a deceased philosopher and his recent commentator), an analyst should still verify if there can be in absentia an interpretation that is clearly charitable to both parties (the inclusive-disjunctive reading above). This task can be achieved by a careful exploration of the goals and positions of disputants, not unlike in Gilbert's (1997) procedures for coalescent argumentation. ${ }^{20}$ However, when the parties are not willing to agree on an interpretation, an analyst should not resort to PC automatically to eliminate interpretive doubt. That is because once the discussants contest each other's interpretation they enter exactly the kind of a situation that is prone to being hit by the paradox of charity. An analyst should be responsive to such a shift to the exclusive-disjunctive situation. The question why be charitable, by principle, to but one of the sides to an argumentative discussion becomes relevant. In particular, why let the protagonist successfully defend her vague or ambiguous position open to multiple interpretations, when the goal of argumentation in a dialectical view is critical testing of that position?

The situation of an interpretive doubt- the condition sine qua non for the application of PC, as understood here-is a problem triggered by the protagonist's lack of precision. Vagueness, ambiguity, and incompleteness especially when deliberate do not deserve a charitable treatment, if only because they may be attempted for manipulative reasons - a result in line

\footnotetext{
${ }^{19}$ As I argued elsewhere, an intersubjective agreement is preferable over an arguer's pronouncements of what "she actually meant": "Arguers [...] may be mistaken, vague or even dishonest in referring to and interpreting their own past expressions and thus, deliberately or not, they may deny previously incurred commitments" (Lewiński 2011: 484). See also n. 7 above.

${ }^{20} \mathrm{I}$ will leave for further consideration interesting clashes; for instance, when there seems to be a rather unequivocal interpretation of an utterance, but arguers agree on a different one; or when an arguer approves an interpretation that is uncharitable to her, while some charitable reading is also plausible.
} 
with Govier's. The gamble of a vague arguer, known all too well from political and commercial (Jacobs 1995) discourse, is that $\mathrm{s} /$ he wants to implicitly convey a strong message, while leaving open the option of backing down to the more literal little commitment. Although "some" may thus convey a message similar to "many," perhaps even "most," under critical pressure it may readily be reinterpreted to the mere logical "one or more." Sharp, charity-excluding interpretations (proposed by actual arguers and analysts alike) may thus effectively help to disambiguate claims and reasons advanced by possibly strategically oriented arguers. This seems to be a more realistic view that does not require idealistic standards of fraction-free rational co-operation, yet preserves the rational-critical core of much theorizing about argumentation.

Second, even if PC, in its deflated, minimal role, may yield paradoxical results and thus cannot be "automatically" applied, that does not mean that it cannot be applied altogether. Rather, it should be applied depending on important contextual clues. Such clues may be insufficient in precisely determining a plausible sense, reference, and a pragmatic force of a given piece of argumentative discourse, but they may further suffice in deciding how to apply PC. Coming back to our example: if the analyst reconstructs charitably only the protagonist's argumentation, and thus takes "some" as "one or more," then the antagonist's critical reaction containing "three or more" is evaluated as a straw man, an unreasonable form of criticism (Lewiński 2011). In this case, the analyst optimizes chances for a successful defense of the protagonist's position, that is, she exhibits a certain "constructive bias." If, on the contrary, the analyst reconstructs charitably only the antagonist's naïve interpretation (expressed in her critical reaction) and thus allows for "three or more" to be a legitimate interpretation of "some," then, obviously, A's reaction is not a straw man. In this case, in accordance with the agonistic spirit of critical rationalism brought to bear on dialectical theories of argumentation (van Eemeren \& Grootendorst 1988; see Adler 1982), the analyst optimizes chances for a successful falsification of the protagonist's position by the antagonist. That is to say, he shows a "critical bias." In this way, being charitable to only one of the arguers amounts to taking sides. ${ }^{21}$ Following

21 Despite this difficulty, Walton, for example, calls for applying PC exclusively to the protagonist (in his terminology "the respondent"): "If the respondent is not present, as is typically the case with the kinds of cases cited as examples of the [straw man] fallacy in the logic textbooks, and evaluated in a logic class, or case study, then the evaluators should be required to go very strictly by the existing discourse, using the principle of charity in fairly interpreting that text of discourse. Here, the respondent must be given the benefit of the doubt, where competing interpretations may be more or less 
this distinction, let us assume for simplicity's sake that each ambiguous expression can be disambiguated in either a constructive way that facilitates a successful defense of the protagonist's standpoint or a critical way that facilitates a successful critique of the protagonist's standpoint by the antagonist. In each case, an analyst has to decide which of the ways to take. This decision should be based on contextual information. After all, the resolution of a given paradox, rather than resting solely on logical considerations, is "a matter of practical policies determined by the purposive considerations operative in the context at issue" (Rescher 2001: 277).

As argued elsewhere (Lewiński 2011), various institutional contexts of argumentation, or argumentative activity types (van Eemeren \& Houtlosser 2005), can themselves be divided into either constructive or critical, depending on what is at stake in a given context of argumentative discussion. Some activities, because of their importance in the context of the institution, require a very high standard of proof for the standpoints advanced by the protagonist. Such is the case, for example, with legal trials and blind academic reviews in which the correctness of the propounded standpoints has to be established "beyond reasonable doubt," if they are to be institutionally accepted. "Reasonable doubt" includes doubt regarding the interpretation of particular terms and expressions. Charity (or giving the benefit of the doubt) would amount to accepting possibly unwarranted claims, and this risk is not allowed in legal trials or academic reviews. In these contexts, the protagonist (prosecutor, the author of a manuscript) is expected to face tough criticisms by the antagonist (judge, peer reviewer), who is expected to expose weaknesses of argumentation, including weaknesses in formulation. In contrast, other activities are governed by general expectations of cooperativeness and even preference for agreement (Grice 1975; Jackson \& Jacobs 1980; Pomerantz 1984). This applies to some highly institutionalized forms of argumentative discussion, such as class-room instruction, and many loose, informal discussions alike. These activities are meant to primarily realize goals other than a strict, "merciless" critical evaluation of each and every bit of argumentation. They facilitate transfer of knowledge, exploration of common ground, or maintenance of relationships, and are strongly constrained by the pressures of politeness and face-saving. Moreover, there are a great many institutional contexts for collaborative decision-making that typically require a constructive attitude. In argumentative terms, a constructive attitude amounts to criticizing someone else's argumentation only if one can advance and defend a better posi- 
tion of her own, Therefore protagonists are given the benefit of the doubt, while antagonists acquire the onus of proof.

My contention is that the analyst's inclination towards either a constructive bias that credits the protagonist with charity, or a critical bias that favors the critical edge of antagonist's interpretation should depend on such contextual factors. The paradox of charity is much less acute if the analyst resorts to institutionally recognized solutions. For instance, in an Anglo-American tradition of a criminal trial, by presumption of innocence the benefit of the doubt (including interpretive doubt) is always given the accused. In contrast, the prosecutor's case is to be treated with utmost critical attention. If we take the prosecutor to be the protagonist of the standpoint " $\mathrm{X}$ is guilty," then we should be charitable with the antagonist's (the accused) doubt or criticism of this standpoint. No judge applying PC to the prosecutor's closing argument is a serious judge. Court of appeals would no doubt meticulously wipe out any traces of charity, if such were the case. By contrast, a continuously critical teacher who does nothing but diligently exposes her students' lapses in reasoning on each possible occasion is most likely a nitpicking "jerk" who fails to fulfill the basic requirements of a successful educator. Conventionally, it is students who should be granted the benefit of the doubt in a class-room environment and a principal or a parents' board can come to the rescue if this convention is not abided by.

Briefly, then, there seems to be a strong contextual variation when it comes to the requirements of charity and, if this indeed is the case, this variation should be taken into account by an analyst who pursues the goal of an adequate reconstruction and evaluation of natural, contextually-bound argumentation. $^{22}$

The outcome of these investigations is a more precise formulation of the principle of charity that addresses the problems of its consistent application:

The principle of charity is to be followed only in cases of interpretive doubt by an argumentation ana-

\footnotetext{
${ }^{22}$ Walton, in his discussion of the rules of dialectical interpretation of ambiguous terms, notices, somewhat in passing, that " $[\mathrm{t}]$ he rules are also sensitive to the purpose of a type of dialogue in which the argumentation is supposed to be embedded" (2000: 271). But he does not sufficiently follow up on this suggestion, so it is not clear how to apply it. Still, it seems that his (or any other, for that matter) dialectical theory can easily approach what I call here the constructive or critical application of PC in terms of the burden of proof. The arguer who has the burden of proof in a given dialectical situation can be treated critically, and thus uncharitably when it comes to interpretation. Conversely, the other dialectical party, who is free of the burden of proof can be granted the benefit of the doubt, and thus treated charitably.
} 
lyst who applies it either to the protagonist in constructive context or to the antagonist in critical contexts by crediting one of them, respectively, with the strongest justificatory or refutatory interpretation of the discourse.

Moreover, the entire analytic procedure for applying $\mathrm{PC}$ in a dialectical approach to argumentation can be schematically presented (see below). In this way, I hope to have achieved a more nuanced and eventually "more plausible" account of PC in a dialectical analysis and evaluation of argumentation. One immediate application of so circumscribed principle is in the evaluation of alleged straw man attacks - not always should the antagonists' less-than-charitable interpretations be taken as fallacious straw men, especially in critical, competitive contexts (Lewiński 2011).

\section{Procedure for applying $P C$ in a dialectical approach to argumentation}

1. Is there an unequivocal interpretation of expression $x$ ?
No
Go to 2
Yes
Take it!

2. Is there an interpretation of expression $x$ that both parties can agree on?

$\begin{array}{ll}\text { No } \quad- & \text { Yes } \\ & \text { Take it! }\end{array}$

Because:

2.1 They are not able? or 2.2 Not willing to agree? Go to $3 \quad$ Go to 4

3. Is there an interpretation of expression $x$ that is clearly chartable to both parties in absentia?
No
Go to 4
Yes
Take it!

4. If the doubt persists, examine the context of a discussion. If the context is:
4.1 Constructive
Credit the protagonist with the
4.2 Critical
strongest justificatory
interpretation
Credit the antagonist with the strongest refutatory
interpretation

\section{Charity and dialectic}

Not coincidentally, while presented here largely as a problem of practical applicability of PC in actual contexts of argumentative 
discussions, the paradox of charity also reveals some deep theoretical dilemmas. One of them is the already mentioned difference in viewing argumentative discussions as primarily a collaborative (maieutic, heuristic) vs. competitive (elenchic, eristic) undertaking. To be sure, theorists seem to agree that dialectics in all forms hinges upon a balanced combination of the collaborative and competitive elements, ${ }^{23}$ but different formulations of dialectical models involve a certain tilt towards one of these elements. Some stress the competitive nature of argumentative encounters where the ultimate goal is to fully resolve or at least minimize disagreement through critical testing of opposing points of view. This is clear in pragma-dialectics, especially after the introduction of the concept of strategic maneuvering, Walton and Krabbe's dialectic, ${ }^{24}$ Johnson's account of the dialectical tier, and Jackson and Jacobs's normative pragmatics. Others, such as advocates of the Habermasian idea of rational consensus and Gilbert's theory of coalescent argumentation, propose a consensualistic view where the emphasis is on maximizing agreement through exploring the potential for the differing positions to coalesce. Quite clearly, my position sketched in this paper draws more explicitly on the competitive dialectical approaches. However, it is not necessarily incompatible with the consensus-seeking theoretical positions such as Gilbert's or Govier's for at least two reasons.

First, to repeat Davidson's dictum, "disagreement and agreement alike are intelligible only against a background of massive agreement" (Davidson 1973: 324). Therefore, argumentation as a verbal practice cannot be successful when there is no collaboration and common ground whatsoever between arguers ("deep disagreement"), nor does the notion fully apply to the cases where there is no disagreement or at least doubt between arguers ("preaching to the already converted"). It is thus neither coincidental nor paradoxical that competitive dialectical theories, such as pragma-dialectics or Walton's new dialectic, draw heavily on Gricean ideas of rational co-operation, and that consensualistic theories define argumentation as a verbal practice "centred on an avowed disagreement" (Gilbert 1997: 104). The differences, to repeat,

\footnotetext{
${ }^{23}$ See e.g. Krabbe (2009); Gilbert, recounting Perelman and OlbrechtsTyteca's $(1958 / 1969, \S 8)$ identification of pure heuristic discussions and decidedly eristic debates, remarks that "most dialogues fall between the extremes and involve some aspects of both" (1997: 7).

${ }^{24}$ Note the difference between the more maieutic Permissive Persuasion Dialogue and more elenchic Rigorous Persuasion Dialogue (Walton \& Krabbe 1995: Ch. 4), as well as between collaborative dialogue types, such as inquiry, and conflictual ones, such as eristics and negotiation (op. cit.: Ch. 3; Krabbe 2009).
} 


\section{Marcin Lewiński}

are of emphasis rather than of definitional elements. For instance, when Gilbert claims that in coalescent argumentation "the goal is to locate those points of belief and/or attitude that are held in common by the conflictual positions" (1995: 846), there is no incompatibility with the pragma-dialectical "intersubjective procedures" (van Eemeren \& Grootendorst 2004: 145ff.) designed to do exactly this within the context of a critical discussion.

Second, all the above-mentioned argumentation theories are strongly contextualistic; they share the basic assumption that argumentation is a situated human activity that derives many of its properties from the contextual conditions of its performance. Hence a different language game, dialogue type, activity type, or argumentation design can differently shape actual instances of argumentation, and analysts should be sensitive to these differences. Again, despite significant theoretical differences in detail, this much is shared between competition-based and consensualistic approaches discussed here. This is also the path I have taken in this essay by arguing for an adequate contextual implementation of either critical or constructive interpretive standards. While focusing on competitive argumentative endeavors, I clearly include close consideration of more collaborative contexts into the procedure for interpreting vague discourse and discuss the application of PC in collaboration-oriented argumentative activities central to scholars such as Gilbert.

Related to such important differences within a dialectical perspective is a yet deeper question of the proper, or most feasible, functions of dialectical reasoning. Philosophers who propagate the truth-tracking (confirmatory) potential of dialectics would be inclined to perceive as the basic rational stance the building up of the strongest argument for a position, so as to get the best out of the reasoning for each position and see if with charitable amendments it can reveal some aspects of truth. That is analogous to the constructive bias I described above. By contrast, those who take as the dominant trait of dialectics its errorcorrecting (falsificationist) function, would rather systematically review all possible objections against a position, in order to find the weaknesses of each proposal; that should eventually lead to corrections getting us closer to truth as a somewhat hidden regulative ideal. This position favors the critical bias mentioned before. Such deep-seated philosophical inclinations have a clear bearing on theorizing dialectic today (see discussions between Biro \& Siegel 2008; Botting 2010; Garssen \& van Laar 2010; Lumer 2012) and in the past, at least ever since the SocraticPlatonic notion of dialectical method merged the maieutic element of discovering truth with the critical elenchus (e.g., Spranzi 2011). 
The present discussion of the paradox of charity merely signals rather than resolves such issues. Although the approach to PC in argumentation theory I have proposed here is derived from the modest error-correcting and competitive view of dialectic, it seems relevant to the other view as well. Thanks to that, it provides a rationale for applying $\mathrm{PC}$ within both dialectical perspectives, not only the truth-tracking one, which has traditionally advocated the use of PC because of its supposed truthsupporting capacity.

\section{Conclusion}

The philosophical study of reasoning and argumentation has regularly been plagued by more or less malignant paradoxes (e.g., Rescher 2001; Sorensen 2003). Most famous of them are the Liar's paradox and Russell's paradox that revolve around basic logical problems such as self-reference and are hotly debated until this very day. The paradoxes that PC generates not only differ from semantic and set-theoretical paradoxes because they concern pragmatic problems of choice and decision, but also because they are benign by virtue of being resolvable. The paradox of irrationality that arises from the requirement of applying rationality-preserving $\mathrm{PC}$ while ascribing irrationality can be avoided in philosophy of language by (charitably) following Davidson's argument that the detection of errors in reasoning is by no means on a collision course with charity. This result is fortunate for argumentation theory, for it can easily import PC in the philosophical sense, without erasing the problems of fallacies and other infelicities of reasoning. If this were not the case, PC would undermine the crucial goal of argumentation theory, that is, critical appraisal of natural argumentation, typically connected to fallacy attribution. But then again, argumentation theory quickly generates its own paradox, which I simply call the paradox of charity, by reconceptualizing PC in the direction of supporting an arguer in her ambiguous or incomplete formulation of arguments. An arguer is either the protagonist or the antagonist, and an analyst who grants charity to but one of them, easily becomes uncharitable to the other. This paradox can be solved by applying only a minimal PC and only under close contextual scrutiny.

Acknowledgements: I thank Frans van Eemeren, Hans Hansen, João Sàágua, Lilian Bermejo-Luque, Ralph Johnson, and two anonymous referees for Informal Logic for their insightful comments provided at different stages of my work on the paper. 
Its completion was possible thanks to two grants of the Portuguese Foundation for Science and Technology (FCT): PTDC/FIL-FIL/10117/2009 and SFRH/BPD/74541/2010.

\section{References}

Adler, J.E. (1982). Why be charitable? Informal Logic Newsletter, 4(2): 15-16.

Adler, J.E. (1994). Fallacies and alternative interpretations. Australasian Journal of Philosophy, 72(3): 271-281.

Adler, J.E. (1996). Charity, interpretation, fallacy. Philosophy and Rhetoric, 29(4): 329-343.

Aristotle. (1997). Topics. Books I and VIII (trans., intr., and notes by R. Smith). Oxford: Clarendon Press.

Austin, J.L. (1962). How to do things with words. Oxford: Oxford University Press.

Barth, E.M., \& Krabbe, E.C.W. (1982). From axiom to dialogue. A philosophical study of logics and argumentation. Berlin/New York: Walter de Gruyter.

Berg, J. (1987). Interpreting arguments. Informal Logic, 9(1): 13-21.

Bermejo-Luque, L. (2011). Giving reasons. Dordrecht: Springer. Blair, J.A. (1998). The limits of the dialogue model of argument. Argumentation, 12(3): 325-339.

Botting, D. (2010). A pragma-dialectical default on the question of truth. Informal Logic, 30(4): 413-434.

Davidson, D. (1973). Radical interpretation. Dialectica, 27(3-4): 313-328.

Davidson, D. (1974). On the very idea of a conceptual scheme. Proceedings and Addresses of the American Philosophical Association, 47: 5-20.

Davidson, D. (1994). Radical interpretation interpreted. Philosophical Perspectives, 8, Logic and Language: 121-128.

Davidson, D. (2004). Paradoxes of irrationality. In: D. Davidson, Problems of irrationality, pp. 169-187. Oxford: Oxford University Press. (Originally published in 1982.)

Dennett, D.C. (1971). Intentional systems. The Journal of Philosophy, 68(4): 87-106.

Eemeren, F.H. van. (2010). Strategic maneuvering in argumentative discourse: Extending the pragma-dialectical theory of argumentation. Amsterdam: John Benjamins.

Eemeren, F.H. van, \& Grootendorst, R. (1988). Rationale for a pragma-dialectical perspective. Argumentation, 2(2): 271291. 
Eemeren, F.H. van, \& Grootendorst, R. (1992). Argumentation, communication, and fallacies: A pragma-dialectical perspective. Hillsdale, NJ: Lawrence Erlbaum.

Eemeren, F.H. van, \& Grootendorst, R. (2004). A systematic theory of argumentation: The pragma-dialectical approach. Cambridge: Cambridge University Press.

Eemeren, F.H. van, Grootendorst, R., Jackson, S., \& Jacobs, S. (1993). Reconstructing argumentative discourse. Tuscaloosa: University of Alabama Press.

Eemeren, F.H. van, \& Houtlosser, P. (1999). Strategic manoeuvring in argumentative discourse. Discourse Studies, 1(4): 479-497.

Eemeren, F.H. van, \& Houtlosser, P. (2005). Theoretical construction and argumentative reality: An analytic model of critical discussion and conventionalised types of argumentative activity. In D. Hitchcock (Ed.), The uses of argument: Proceedings of a conference at McMaster University, pp. 75-84. Hamilton, ON: Ontario Society for the Study of Argumentation.

Fodor, J., \& Lepore, E. (1994). Is radical interpretation possible? Philosophical Perspectives, 8, Logic and Language: 101-119.

Garssen, B.J., \& Laar, J.A. van. (2010). A pragma-dialectical response to objectivist epistemic challenges. Informal Logic, 30(2): 122-141.

Gauker, C. (1986). The principle of charity. Synthese, 69(1): 125.

Gilbert, M.A. (1995). Coalescent argumentation. Argumentation, 9(5): 837-852.

Gilbert, M.A. (1997). Coalescent Argumentation. Mahwah, NJ: Lawrence Erlbaum.

Glüer, K. (2006). The status of charity I: Conceptual truth or a posteriori necessity? International Journal of Philosophical Studies, 14(3): 337-359.

Gough, J., \& Tindale, C. (1985). 'Hidden' or 'missing' premises. Informal Logic, 7(2): 99-106.

Govier, T. (1981). Uncharitable thoughts about charity. Informal Logic Newsletter, 4(20): 5-6.

Govier, T. (1982). On Adler on charity. Informal Logic Newsletter, 4(4): 10-11.

Govier, T. (1987). A new approach to charity. In Problems in argument analysis and evaluation, pp. 133-158. Dordrecht: Foris.

Grice, H.P. (1975). Logic and conversation. In P. Cole \& J.L. Morgan (Eds.), Syntax and semantics, Vol. 3: Speech acts, pp. 41-58. New York: Academic Press.

Hamblin, C.L. (1970). Fallacies. London: Methuen. 
Henderson, D.K. (1987a). The principle of charity and the problem of irrationality (Translation and the problem of irrationality). Synthese, 73(2): 225-252.

Henderson, D.K. (1987b). A solution to Davidson's paradox of irrationality. Erkenntnis, 27(3): 359-369.

Jackson, S., \& Jacobs, S. (1980). Structure of conversational argument: Pragmatic bases for the enthymeme. Quarterly Journal of Speech, 66(3): 251-265.

Jacobs, S. (1995). Implicatures and deception in the arguments of commercial advertising. In F.H. van Eemeren, R. Grootendorst, J.A. Blair, \& C.A. Willard (Eds.), Special fields and cases: Proceedings of the third ISSA conference on argumentation, vol. IV, pp. 579-592. Amsterdam: SicSat.

Johnson, R.H. (1981). Charity begins at home. Informal Logic Newsletter, 3(3): 4-9.

Krabbe, E.C.W. (2009). Cooperation and competition in argumentative exchanges. In H.J. Ribeiro (Ed.), Rhetoric and argumentation in the beginning of the XXIst century, pp. 111126. Coimbra: University of Coimbra Press.

Levin, J. (1988). Must reasons be rational? Philosophy of Science, 55(2): 199-217.

Levinson, S.C. (2000). Presumptive meanings: The theory of generalized conversational implicature. Cambridge, MA: MIT Press.

Lewiński, M. (2011). Towards a critique-friendly approach to the straw man fallacy evaluation. Argumentation, 25(4): 469497.

Lewiński, M. (2012). Public deliberation as a polylogue: Challenges of argumentation analysis and evaluation. In H. J. Ribeiro (Ed.), Inside arguments: Logic and the study of argumentation, pp. 223-245. Newcastle upon Tyne: Cambridge Scholars Publishing.

Lewis, D. (1974). Radical interpretation. Synthese, 27(3-4): 331344.

Lumer, C. (2012). The epistemic inferiority of pragmadialectics: A reply to Botting. Informal Logic, 32(1): 51-82.

Manning, R. (1983). A more charitable principle of charity. Informal Logic Newsletter, 5: 20-21.

Pagin, P. (2006). The status of charity II: Charity, probability, and simplicity. International Journal of Philosophical Studies, 14(3): 361-383.

Paglieri, F., \& Woods, J. (2011a). Enthymematic parsimony. Synthese, 178(3): 461-501.

Paglieri, F., \& Woods, J. (2011b). Enthymemes: From reconstruction to understanding. Argumentation, 25(2), $127-$ 139. 
Perelman, Ch., \& Olbrechts-Tyteca, L. (1969). The new rhetoric: A treatise on argumentation (transl. by J. Wilkinson $\&$ P. Weaver. Notre Dame: University of Notre Dame Press. (Original work published 1958.)

Pomerantz, A. (1984). Agreeing and disagreeing with assessments: Some features of preferred/dispreferred turn shapes. In J.M. Atkinson \& J. Heritage (Eds.), Structures of social action: Studies in conversational analysis, pp. 57-101. Cambridge: Cambridge University Press.

Quine, W.V.O. (1960). Word and object. Cambridge, MA: MIT Press.

Rescher, N. (2001). Paradoxes: Their roots, range, and resolution. Chicago: Open Court.

Scriven, M. (1976). Reasoning. New York: McGraw Hill.

Siegel, H., \& Biro, J. (2008). Rationality, reasonableness, and critical rationalism: Problems with the pragma-dialectical view. Argumentation, 22(2): 191-203.

Snoeck Henkemans, A. F. (1992). Analysing complex argumentation: The reconstruction of multiple and coordinatively compound argumentation in a critical discussion. Amsterdam: SicSat.

Sorensen, R. (2005). A brief history of the paradox: Philosophy and the labyrinths of the mind. Oxford: Oxford University Press.

Spranzi, M. (2011). The art of dialectic between dialogue and rhetoric: The Aristotelian Tradition. Amsterdam: John Benjamins.

Thagard, P., \& Nisbett, R.E. (1983). Rationality and charity. Philosophy of Science, 50(2): 250-267.

Vahid, H. (2010). Rationalizing beliefs: Evidential vs. pragmatic reasons. Synthese, 176(3): 447-462.

Verdung, E. (1983). Systematic interpretation and the principle of charity. Informal Logic Newsletter, (5): 21-22.

Walton, D.N. (1996). The straw man fallacy. In J. van Benthem, F.H. van Eemeren, R. Grootendorst \& F. Veltman (Eds.), Logic and argumentation, pp. 115-128. Amsterdam: Royal Netherlands Academy of Arts and Sciences.

Walton, D.N. (2000). New dialectical rules for ambiguity. Informal Logic, 20(3): 261-274.

Walton, D.N., \& Krabbe, E.C.W. (1995). Commitment in dialogue: Basic concepts of interpersonal reasoning. Albany: State University of New York Press.

Walton, D.N., \& Reed, C.A. (2005). Argumentation schemes and enthymemes. Synthese, 145(3): 339-370.

Wilson, N.L. (1959). Substances without substrata. The Review of Metaphysics, 12(4): 521-539. 